\title{
Experimental Colitis Enhances the Rate of Antinociceptive Tolerance to Morphine via Peripheral Opioid Receptors $\$$
}

\author{
Essie Komla, David L. Stevens, Yi Zheng, Yan Zhang, William L. Dewey, \\ and Hamid I. Akbarali \\ Departments of Pharmacology and Toxicology (E.K., D.L.S., W.L.D., H.I.A.) and Medicinal Chemistry (Y.Zhe., Y.Zha.), Virginia \\ Commonwealth University, Richmond, Virginia
}

Received January 28, 2019; accepted June 24, 2019

\begin{abstract}
Opioids are highly effective analgesics, however, their therapeutic use is limited by adverse effects that include respiratory depression, dependence, and tolerance. Inflammation has been implicated as a significant driver for the development of tolerance to opioids. Recent studies show that chronic morphine in mice results in gut microbial dysbiosis and inflammation in the colon. In the present study, we examined whether colonic inflammation results in tolerance to the antinociceptive effects of morphine. Colonic inflammation was induced in mice by intrarectal administration of 2,4,6-trinitro-benzene sulfonic acid. The development of antinociceptive tolerance was determined by warm-water tail-immersion assay in mice implanted with 25-, 50-, or 75-mg morphine pellet. Colonic inflammation significantly enhanced the rate at which tolerance developed in each cohort of chronic morphine-treated mice. At the lowest dose of morphine pellet $(25 \mathrm{mg})$, antinociceptive tolerance only developed in the presence of colonic inflammation, whereas in 50- and 75-mg pelleted mice, tolerance developed faster in the inflamed animals than in the noninflamed mice. The enhanced antinociceptive tolerance was attenuated with daily administration of peripheral opioid receptor antagonist, $6 \beta-N$-heterocyclic-substituted naltrexamine derivative
\end{abstract}

[17-cyclopropylmethyl-3,14 $\beta$-dihydroxy-4,5 $\alpha$-epoxy-6 $\beta$-[(4'pyridyl) acetamido]morphinan (NAP)], irrespective of colonic inflammation. Collectively, these findings show that the rate of tolerance to morphine antinociception is exaggerated in the presence of colonic inflammation, and tolerance is prevented by a peripheral $\mu$-opioid receptor antagonist. These studies suggest a peripheral component to the development of antinociceptive tolerance to opioids. Furthermore, peripherally selective opioid antagonists may be useful adjuncts in opioid-based pain management.

\section{SIGNIFICANCE STATEMENT}

This study supports the notion that inflammation influences the development of antinociceptive tolerance to chronic morphine exposure. We found that, in the presence of colonic inflammation, the rate of development of tolerance to the antinociceptive effects of morphine increased. We also found that treatment with a peripheral opioid receptor antagonist prevented morphine antinociceptive tolerance. Increasing opioid intake during an inflammatory state would result in decreased analgesia and enhanced analgesic tolerance, which puts patients with inflammatory bowel diseases, inflammatory joint diseases, and sickle cell anemia at risk for heavy opioid use.

\section{Introduction}

Opioids are frequently used for the treatment of moderate to severe pain and noncancer pain. Their therapeutic use is primarily limited due to the adverse effects with chronic use, particularly the development of tolerance and dependence. Tolerance to the various pharmacological effects of opioids develops to different degrees (Hayhurst and Durieux, 2016), with tolerance to respiratory depression occurring at a slower rate than analgesic and euphoric effects, which may be one of the primary reasons for overdose-related deaths.

This work was supported by the National Institutes of Health National Institute on Drug Abuse [Grants R01 DA024009, R01 DA036975, R01 DA036975-04S, and P30 DA033934].

https://doi.org/10.1124/jpet.119.256941.

S This article has supplemental material available at jpet.aspetjournals.org.
Mechanisms by which tolerance occurs are complex and not well understood. We and others have previously reported that chronic morphine administration in mice alters the gut microbiome, which affects the development of antinociceptive tolerance, dependence, and reward pathways (Meng et al., 2013; Kang et al., 2017; Lee et al., 2018). It has also been reported that chronic morphine induces neuroinflammation in the brain and spinal cord via glial cell activation (Hutchinson et al., 2008; Milligan and Watkins, 2009), and in the gastrointestinal tract via cytokines released from the enteric glia (Bhave et al., 2017). Studies have suggested that inflammation may contribute to morphine tolerance (Song and Zhao, 2001; Raghavendra et al., 2002; Watkins et al., 2005), thus blocking inflammation with the glial-modulating agent propentofylline (Raghavendra et al., 2004) or with neutralizing antibodies to interleukin 6 (IL-6), tumor necrosis factor

ABBREVIATIONS: FITC, fluorescein isothiocyanate; IBD, inflammatory bowel disease; IL, interleukin; MOR, $\mu$-opioid receptor; MP, morphine pellet; \%MPE, percentage of maximum possible effect; NAP, 17-cyclopropylmethyl-3,14 $\beta$-dihydroxy-4,5 $\alpha$-epoxy-6 $\beta$-[(4'pyridyl)acetamido] morphinan; PCR, polymerase chain reaction; PP, placebo pellet; 18S rRNA, 18 S ribosomal ribonucleic acid; TLR4, Toll-like receptor 4; TNBS, 2,4,6-trinitro-benzene sulfonic acid; VEH, vehicle. 
$\alpha(T N F-\alpha)$, or with interleukin 1 receptor antagonist (IL-1Ra) (Johnston et al., 2004; Hutchinson et al., 2008) attenuated the development of antinociceptive tolerance at the spinal level in animal models. Additionally, depletion of gut bacteria with antibiotics also prevented the induction of antinociceptive tolerance as well as inflammation (Kang et al., 2017).

Clinical supporting evidence from the Crohn's Therapy, Resource, Evaluation, and Assessment Tool registry, comprising over 6000 Crohn's disease patients, showed that narcotic use carried a high risk for mortality and enhanced infection (Cross et al., 2005; Lichtenstein et al., 2006, 2012). Since chronic morphine also induces inflammation, the combination of inflammatory bowel disease (IBD), such as Crohn's disease, and opioids likely enhances the severity of the disease. According to Targownik et al. (2014), IBD patients taking opioids are 3 times more likely to become heavy opioid users than their matched controls. It is possible that heavy opioid usage could be due to the development of tolerance to opioids. Furthermore, it is not known whether the increased inflammatory response from the combination of both IBD and opioids alters the rate at which tolerance to the opioid develops. This prompted us to investigate the rate of development of tolerance to the antinociceptive effects of morphine in a model of experimental colitis. Peripheral $\mu$-opioid receptors have been implicated in the development of tolerance, as their deletion in dorsal root ganglia nociceptors has been shown to prevent morphine tolerance (Corder et al., 2017). We therefore tested the effect of peripheral opioid receptor antagonist on the development of antinociceptive tolerance in the colonic inflammation model. Notably, our results demonstrate that colonic inflammation enhances the rate of tolerance to morphine, which is abrogated by a peripheral opioid antagonist.

\section{Materials and Methods}

Animals. Male Swiss Webster mice weighing 25-35 g (Harlan Sprague Dawley, Inc., Fredrick, MD) were housed five per cage in an animal care facility under a 12-hour light/dark cycle with food and water available ad libitum. The experimental protocol was approved by the Institutional Animal Care and Use Committee at Virginia Commonwealth University.

Experimental Model of Colitis. Colonic inflammation was induced by administering mice with 2,4,6-trinitro-benzene sulfonic acid (TNBS) solution containing a 1:1 dilution mixture of $2.5 \%$ picrylsulfonic acid solution [5\% (w/v) in $\mathrm{H}_{2} \mathrm{O}$; Sigma-Aldrich, St. Louis, MO] and $50 \%$ ethanol. One hundred microliters of the mixture was administered to each animal intrarectally. Control animals received $100 \mu \mathrm{l}$ of a 1:1 dilution mixture of saline and $50 \%$ ethanol as vehicle. For chronic morphine experiments, morphine pellets (MPs; $25-$, 50- $(2 \times 25)$, or 75mg; National Institute on Drug Abuse) or placebo pellets (PPs; National Institute on Drug Abuse) were implanted under anesthesia, and then the TNBS solution was immediately administered rectally. For the reversal-of-tolerance study, the peripheral antagonist, $6 \beta-N$ heterocyclic-substituted naltrexamine derivative [17-cyclopropylmethyl3,14 $\beta$-dihydroxy-4,5 $\alpha$-epoxy-6 $\beta$-[(4'pyridyl)acetamido]morphinan (NAP)], was injected subcutaneously $(0.5 \mathrm{mg} / \mathrm{kg})$ immediately after the morphine pelleting and the TNBS administration. NAP was dissolved in double distilled water $\left(\mathrm{ddH}_{2} \mathrm{O}\right)$; control mice received double distilled water $\left(\mathrm{ddH}_{2} \mathrm{O}\right)$ as vehicle $(10 \mu \mathrm{l} / \mathrm{g})$. NAP or vehicle was injected once daily for 3 days for mice pelleted with the 75-mg morphine pellet, 4 days for mice pelleted with the 50-mg morphine pellet, and 5 days for mice pelleted with the 25-mg morphine pellet. The overall health of the animals was monitored each day, and their weights were recorded daily.

Nociceptive Response Tests. The warm-water tail-immersion assay was used to measure antinociception. Mice were gently detained in a cloth, and the distal $1 / 3$ of the tail was submerged in a water bath at $56^{\circ} \mathrm{C}$. A baseline latency to tail flick for all placebo-pelleted or naïve mice was between 2 and 4 seconds. A maximum latency of 10 seconds was used to prevent tissue damage. To test for tolerance, an acute morphine challenge dose was administered $(10 \mathrm{mg} / \mathrm{kg}$, s.c.) 30 minutes prior to testing. The tail-withdrawal data obtained from the baseline recording and after the challenge dose of morphine was quantified using the percentage of maximum possible effect (\%MPE) equation: $\% \mathrm{MPE}=[($ challenge time - baseline time $) /(10-$ baseline time $)] \times$ 100. Higher \%MPE indicates less tolerance to morphine.

Cumulative Dose Response. To conduct a dose response, a cumulative dosing schedule was used. On the day of testing, a baseline tail-withdrawal latency was recorded from mice at $56^{\circ} \mathrm{C}$ followed by subcutaneous challenge doses of morphine every 20 minutes. Mice treated with NAP were injected with $0.5 \mathrm{mg} / \mathrm{kg}$ NAP 20 minutes prior to baseline tail-withdrawal latency recording, followed by subcutaneous challenge doses of morphine every 20 minutes using the same paradigm.

Chronic Morphine Treatment. For chronic morphine administration, a 25-, 50- $(2 \times 25)$, or $75-\mathrm{mg}$ MP or PP was implanted subcutaneously on the dorsum. Morphine and placebo pellets were obtained from the National Institute on Drug Abuse. Only 25- and 75 -mg morphine pellets are available. Therefore $2 \times 25$-mg morphine pellets were implanted for the 50-mg morphine-pelleted group. Surgical implantation of the pellets took place under anesthesia (2.5\% isoflurane). Mouse hair was shaved from the base of the neck, and the skin was thoroughly cleansed with $10 \%$ povidone iodine (General Medical Corp., Walnut, CA) and then rinsed with $70 \%$ ethanol. A 1-cm horizontal incision was made at the cleansed area, and the pellet was inserted in the space. The site was closed by stapling the skin with Clay Adams Brand, MikRon AutoClip 9-mm Wound Clips (Becton Dickinson, Franklin Lakes, NJ). The animals were allowed to recover in their home cages, where they remained throughout the experiment until a day before testing day. Mice were habituated to the testing room for 24 hours; mice receiving 25-, 50$(2 \times 25)$, or 75 -mg morphine pellet were tested on days 5,4 , or 3 , respectively.

H\&E Staining. Colon samples were isolated and fecal pellets were gently flushed with $1 \times$ PBS, and then the distal colon was embedded in Optimal Cutting Temperature Compound (Sakura Finetek, Torrance, CA). The embedded tissue was immediately flash frozen in liquid nitrogen and then stored at $-80^{\circ} \mathrm{C}$. The distal colon tissues were cryosectioned at $12 \mu \mathrm{m}$. The cross sections were fixed in $4 \%$ paraformaldehyde in PBS and stained using the standard hematoxylin and eosin (H\&E; Sigma-Aldrich) protocol.

RNA Isolation and Real-Time Polymerase Chain Reaction. Quantitative real-time polymerase chain reaction (PCR) was performed on a Mini-Opticon real-time PCR system (Bio-Rad, Hercules, CA). 18S Ribosomal RNA was used as an internal control. Whole colon tissues were isolated, and total RNA was extracted using TRIzol reagent (Thermo Fisher Scientific, Waltham, MA). The first-strand cDNA synthesis was amplified at $42^{\circ} \mathrm{C}$ for 30 minutes, and subsequent polymerization was performed in a single step using the SensiMix One-Step kit (Bio-Rad). The reaction mixture $(20 \mu \mathrm{l})$ contained $200 \mathrm{nM}$ forward primer, $200 \mathrm{nM}$ reverse primer, $1 \mu \mathrm{l}$ of $2 \times$ SensiMix One-Step buffer, $10 \mathrm{U}$ of RNase inhibitor, and $200 \mathrm{ng}$ of total RNA. The PCR protocol consisted of 40 cycles of denaturation ( 15 seconds at $95^{\circ} \mathrm{C}$ ), annealing $\left(30\right.$ seconds at $\left.58^{\circ} \mathrm{C}\right)$, and extension $\left(30\right.$ seconds at $72^{\circ} \mathrm{C}$ ). Relative expression of the respective genes to $18 \mathrm{~S}$ expression was calculated using the $\Delta \Delta \mathrm{Ct}$ method, and values were expressed as a fold change from the control group. Primers used in this study are Il- $1 \beta$ and $18 \mathrm{~S}$ ribosomal ribonucleic acid (18S $\mathrm{rRNA}$ ).

List of Primers Used for Quantification of 18S rRNA and IL-1 $\beta$. Primers used for quantification of $18 \mathrm{~S} \mathrm{rRNA}$ and IL- $1 \beta$ were as follows:

target: IL-1 $\beta$

sequence: forward: 5'-GTACAAGGAGAACCAAGCAA-3'

reverse: 5'-TGTTGAAGACAAACCGTTTT-3' 
target: 18S rRNA

sequence: forward: 5'-TCAAGAACGAAAGTCGGAGG-3'

reverse: 5'-GGACATCTAAGGGCATCAC-3'.

Cytokine Measure. Enzyme-linked immunosorbent assay (ELISA) was performed to determine the protein level of IL- $1 \beta$ from TNBS- and vehicle (VEH)-treated mouse colon on day 3 . Whole colon tissues were homogenized in cell lysis buffer 2 (R\&D Systems) and incubated on ice for 30 minutes, followed by centrifugation $(10,000 \mathrm{rpm}, 15$ minutes at $4^{\circ} \mathrm{C}$ ). Supernatants were collected into clean tubes and assessed for cytokine content. IL- $1 \beta$ levels were measured using a mouse IL-1 $\beta / \mathrm{IL}-1 \mathrm{~F} 2$ Quantikine ELISA kit (R\&D Systems) following the manufacturer protocol.

Fluorescein Isothiocyanate-Dextran Assay. For in vivo intestinal permeability studies, fluorescein isothiocyanate (FITC)-conjugated dextran (Sigma-Aldrich) was administered by oral gavage $(44 \mathrm{mg} / 100 \mathrm{~g}$ body weight of FITC-labeled dextran). After 4 hours, mice were euthanized using guillotine, and a sample of their whole blood was collected into a heparinized blood collection tube. The collection process was carried out with lights off due to the light sensitivity of the FITC. Blood samples were centrifuged for 15 minutes at $3000 \mathrm{rpm}$ at $15^{\circ} \mathrm{C}$, and plasma was transferred into a new, clean, 1.5-ml tube. Samples were diluted at a $1: 1$ ratio with $1 \times$ PBS. One hundred microliters of diluted samples and standards (serial dilution of FITC-dextran: 0, 125, 250, 500, 1000, 2000, 4000, 6000, and $8000 \mathrm{ng} / \mathrm{ml}$ ) was pipetted into a 96 -well plate in duplicate. FITC concentration was quantified by emission spectrometry (Promega, Madison, WI) at $528 \mathrm{~nm}$ using an excitation wavelength of $485 \mathrm{~nm}$. Sample concentrations were measured against a standard curve of serially diluted FITC-dextran.

Statistical Analysis. GraphPad Prism 7.0 (GraphPad Software, La Jolla, CA) was used for statistical analyses. Data were analyzed using Student's unpaired two-tailed $t$ test, or ordinary two-way ANOVA with multiple comparisons using Tukey' or Bonferroni's post hoc test or ordinary one-way ANOVA with comparison with a single control group using Dunnett's post hoc test, as indicated in the figure legends. Differences were considered significant if $P \leq 0.05$. For the cumulative dose-response studies, nonlinear regression analysis was performed and the best-fit line was generated, followed by repeated-measures two-way ANOVA with Tukey's post hoc test. The results are expressed as the mean value \pm S.E.M.

\section{Results}

Pathologic Characteristics of TNBS-Induced Colitis. Colonic inflammation was induced in mice by $2.5 \%$ TNBS administered intrarectally. Histologic examination of the distal
A
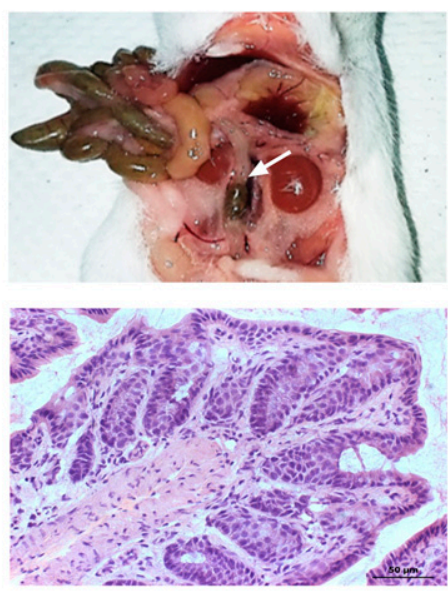

B

D

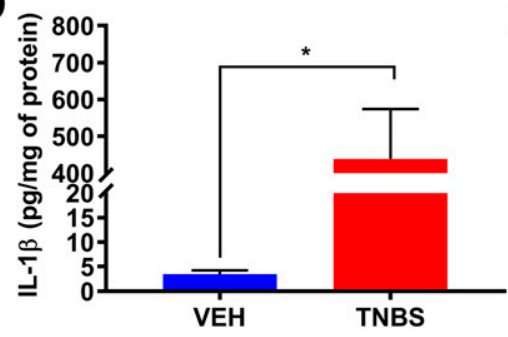

TNBS
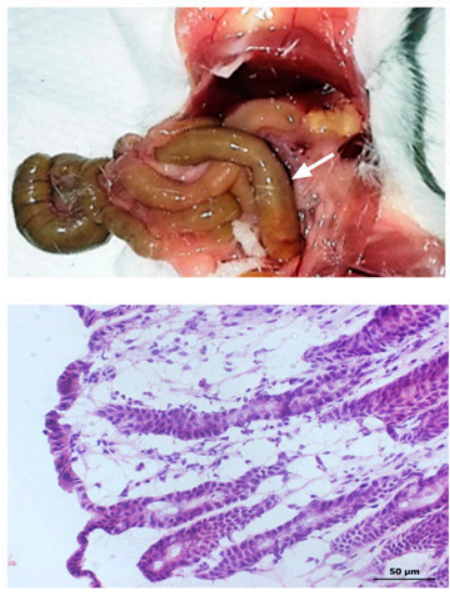

C

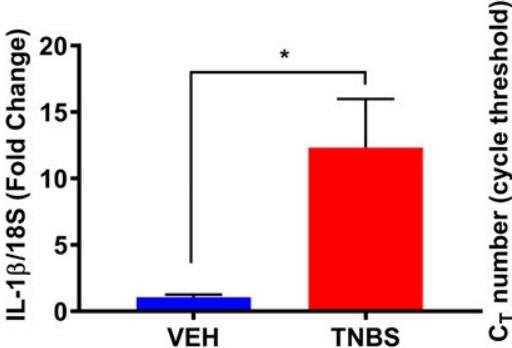

$\mathrm{E}$

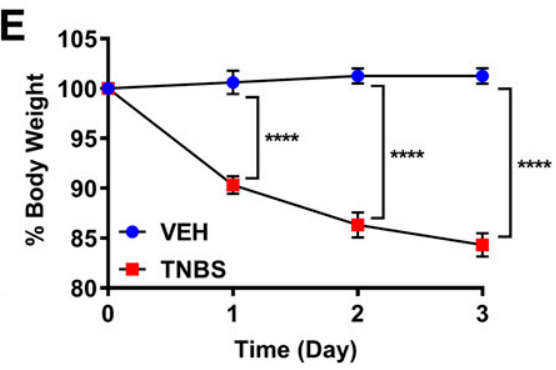

\section{0}

TNBS
Fig. 1. Evaluation of TNBS-induced colitis. (A) Mice treated with TNBS show a clear inflammation of colon, indicated by arrows, compared with vehicle-treated mice. H\&E staining of colon sections demonstrates mucosal damage in TNBS treated mice. Scale bar, $50 \mu \mathrm{m}$. (B) TNBS treatment significantly increases mRNA expression of IL- $1 \beta$ from colon tissues on day 3. $N=6$ /group; $* P=0.0114$ by unpaired $t$ test. (C) Quantitative PCR data are normalized to housekeeping gene 18S rRNA, whose expression is not altered during an inflamed state; ns, not significant. (D) The level of IL$1 \beta$ produced in TNBS-treated mice is significantly increased in colon tissues on day 3 , correlating with the mRNA expression data. $N=5$ /group; $* P=0.0120$ by unpaired $t$ test. (E) Percentage of weight loss of TNBStreated mice is significantly higher than the VEH group. $N=5 /$ group; $* * * * P<0.0001$ by two-way ANOVA with Tukey's post hoc analysis.

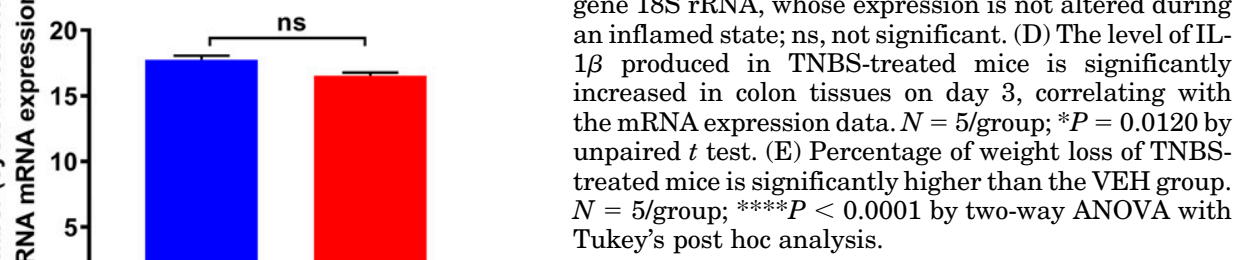


colon by H\&E staining and postmortem necropsy images 3 days after initial TNBS treatment showed an inflamed colon, neutrophil infiltration, and damaged mucosal and crypt architecture compared with the vehicle-treated group (Fig. 1A). The extent of inflammation was assessed by examining inflammatory cytokine IL- $1 \beta$ mRNA expression and protein levels from whole colon tissues using real-time PCR and ELISA, respectively. IL-1 $\beta$ was used as a marker of inflammation, and its expression was normalized with housekeeping gene $18 \mathrm{~S}$ rRNA. Figure 1B shows a significantly higher IL-1 $\beta$ mRNA expression in TNBS-treated animals compared with the vehicle-treated mice. The housekeeping gene 18S rRNA was not altered by TNBS or VEH treatment (Fig. 1C). IL-1 $\beta$ protein levels were similarly higher in TNBS-treated mice (Fig. 1D), consistent with the mRNA expression. In addition, mice were monitored daily for their overall health, and their body weights were recorded. Mice treated with TNBS exhibited a significant weight loss (15\%) after the initial TNBS exposure (Fig. 1E).

Colonic Inflammation Altered the Rate of Antinociceptive Tolerance. A cumulative dose response to morphine was carried out in TNBS- and VEH-treated mice on day 3 following TNBS administration. The morphine dose-response curve was shifted slightly to the left in the TNBS-treated mice compared with the noninflamed mice $\left[\mathrm{VEH} \mathrm{ED} \mathrm{ED}_{50}=4.7 \mathrm{mg} / \mathrm{kg}(4.03-5.47\right.$, 95\% confidence limit (C.L.)); TNBS $\mathrm{ED}_{50}=3.14 \mathrm{mg} / \mathrm{kg}$ (2.58-3.82, 95\% confidence limit (C.L.))] (Fig. 2); however, the two dose-response curves were not significantly different (two-way ANOVA).

To test if the extent of tolerance that develops after chronic morphine is altered by colonic inflammation, TNBS-treated mice were pelleted with either 25-, 50- $(2 \times 25)$, or 75-mg of MP or PP on the day of TNBS administration. TNBS treatment in combination with morphine pelleting resulted in rapid decline in body weight (Fig. 3). There was a 10\%-15\% decrease in body weight with TNBS that was slightly enhanced in the presence of morphine; however, the weight loss did not exceed $18 \%$.

The rate of tolerance to morphine was determined each day by measuring the latency to tail withdrawal in warmwater tail-immersion assay. As shown in Fig. 4 (left panels), as expected, the baseline latency in MP-treated groups was higher on day 1 than in PP-treated groups. Over time, the

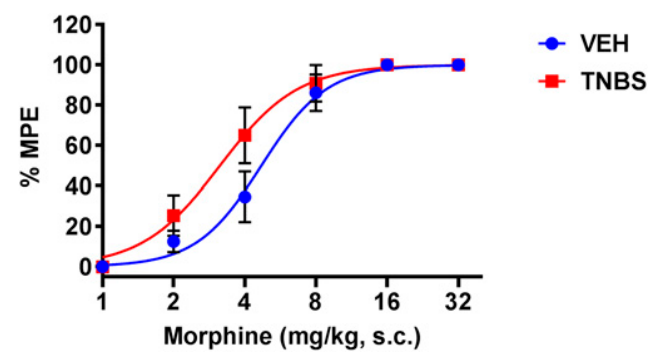

Fig. 2. Dose-response curves to the antinociceptive effect of morphine during TNBS inflammation. A cumulative dose response to morphine $(1,2,4,8,16$, and $32 \mathrm{mg} / \mathrm{kg}$ ) tested in TNBS- and VEH-treated mice on day 3 shows increased morphine potency in TNBS mice compared with VEH mice. $N=9 /$ group, VEH $\mathrm{ED}_{50}=4.7 \mathrm{mg} / \mathrm{kg}$ (4.03-5.47, 95\% confidence limit (C.L.)), TNBS ED $_{50}=3.14 \mathrm{mg} / \mathrm{kg}(2.58-3.82$, 95\% confidence limit (C.L.)). No significant difference between the two dose-response curves ( $P=0.21$ by two-way ANOVA with Tukey's post hoc analysis).
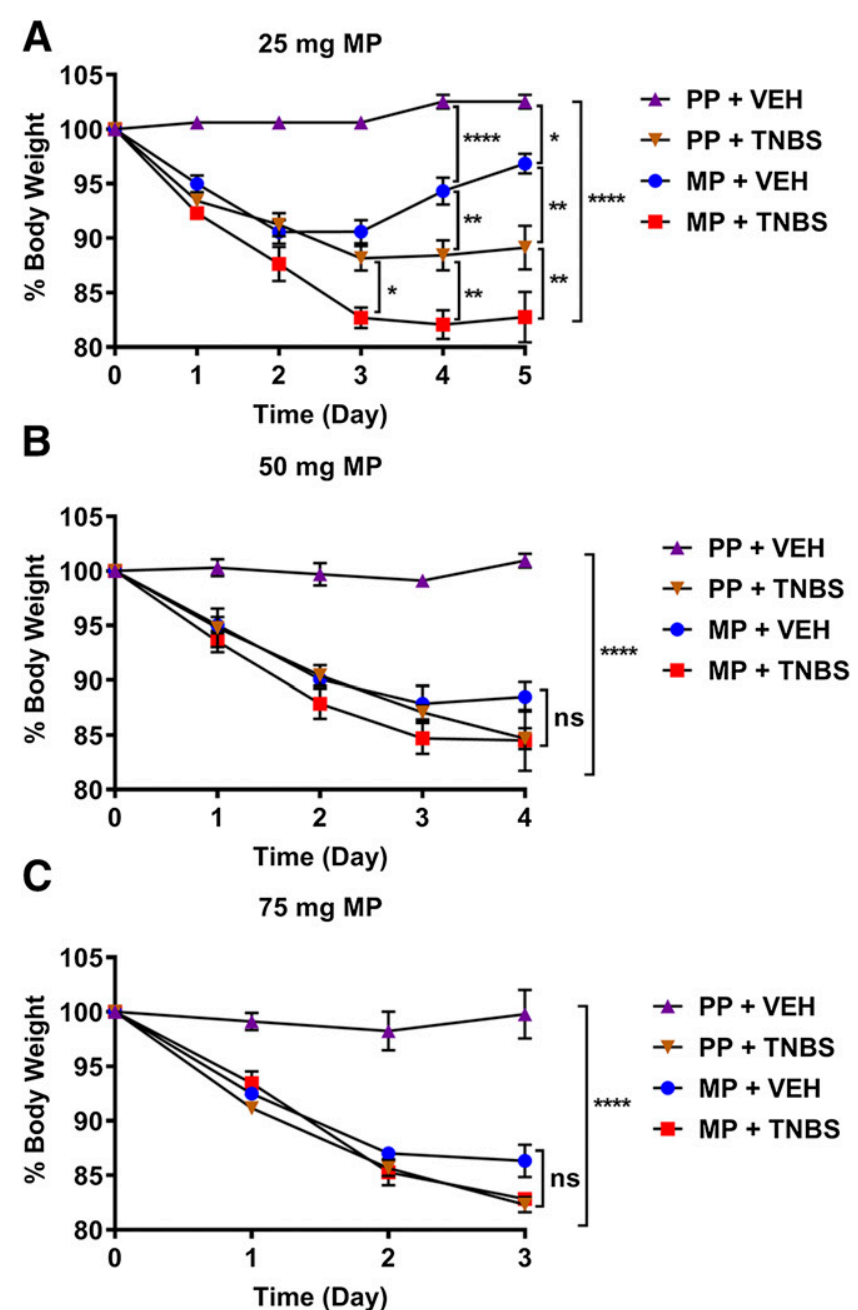

Fig. 3. Percentage of body weight loss in morphine- and TNBS-treated mice. (A-C) Body weight gradually decreased over the course of morphine alone (MP + VEH), TNBS alone (PP + TNBS), or the combination of TNBS and morphine treatment (MP + TNBS) in (A) 25-mg MP group, (B) 50-mg MP groups, and (C) 75-mg MP group. $N=5$ /group; ns, not significant; $* P=0.0311, * * P<0.01$, and $* * * * P<0.0001$ by two-way ANOVA with Tukey's post hoc analysis.

baseline latency of MP-treated mice progressively declined to the level of the PP-treated mice in each of the groups, indicating the loss of morphine's effect. In preliminary studies, mice treated with TNBS and 75-mg morphine pellets had increased mortality; therefore, the subsequent experiments in which mice were treated with both TNBS + MP to determine tolerance were limited to 5 days (25-mg MP), 4 days (50-mg MP), and 3 days (75-mg MP). Tolerance was determined daily in each cohort of mice by a challenge dose $(10 \mathrm{mg} / \mathrm{kg})$ and the $\% \mathrm{MPE}$ was determined (right panels). When the placebo groups were challenged with morphine $(10 \mathrm{mg} / \mathrm{kg})$, they all responded with a maximal antinociception at $100 \% \mathrm{MPE}$. In the morphine-pelleted groups, significant tolerance was observed to a morphine challenge on day 5 in the $25-\mathrm{mg} \mathrm{MP}+\mathrm{TNBS}$ mice $(19.3 \% \pm 4 \% \mathrm{MPE})$. Interestingly, at this dose of morphine pellet, tolerance did not develop in the MP group alone up to 5 days. In the 50-mg MP group, tolerance was enhanced in the MP + TNBS mice $(18.9 \% \pm 13 \% \mathrm{MPE})$ compared with MP mice alone by day 4, and similarly in the 75-mg MP group, early onset of tolerance occurred in the MP + TNBS 


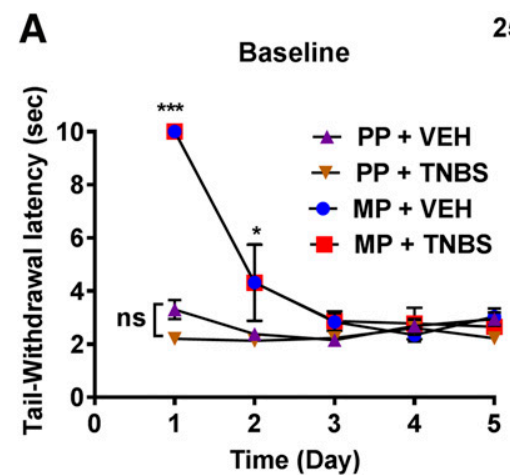

B

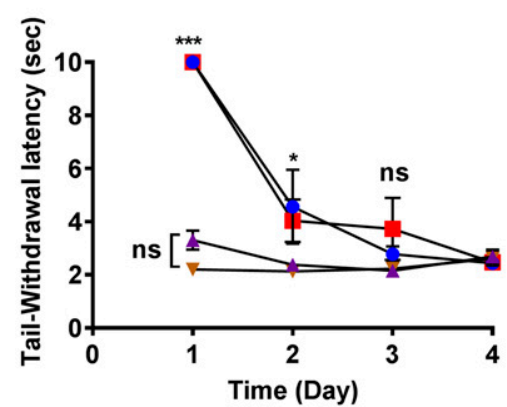

$50 \mathrm{mg}$ MP

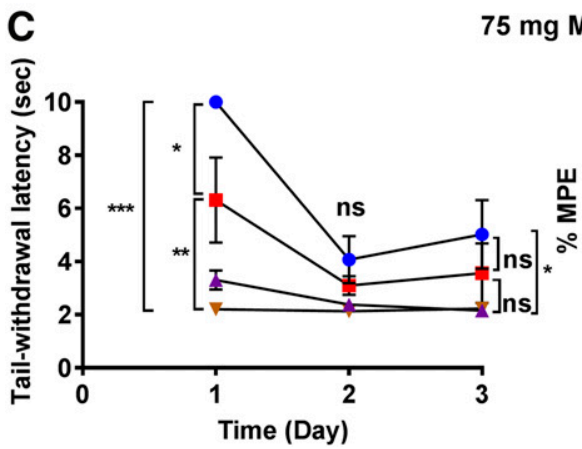

Fig. 4. TNBS-induced colitis enhanced the rate of tolerance development in a dose- and time-dependent manner. (A-C) Daily baseline recording (left panel) shows a progressive loss of morphine response in 25-, $50-$, and 75-mg MP groups over the course of 5, 4, and 3 days, respectively. Daily $10-\mathrm{mg} / \mathrm{kg}$ morphine challenge (right panel) restored the loss of morphine response in all groups except in the 25-mg MP + TNBS group on day 5, 50-mg MP + TNBS group on day 4, and 75-mg MP + TNBS group as early as day 2 , indicating an enhanced development of tolerance in the inflamed mice. (A) MP $+\operatorname{TNBS}(N=5-7 /$ day $)$, $\mathrm{MP}+\mathrm{VEH}(N=5 /$ day $), \mathrm{PP}+\mathrm{TNBS}(N=5 /$ day $), \mathrm{PP}$ $+\mathrm{VEH}(N=5 /$ day $) ; * * * P<0.001$ by two-way ANOVA with Tukey's post hoc analysis. (B) MP + TNBS $(N=5-8 /$ day $), \mathrm{MP}+\mathrm{VEH}(N=5-7 /$ day $), \mathrm{PP}$ $+\operatorname{TNBS}(N=5 /$ day $), \mathrm{PP}+\mathrm{VEH}(N=5 /$ day $)$; ns, not significant; $* P<0.05$ and $* * * P<0.001$ by two-way ANOVA with Tukey's post hoc analysis. (C) MP + TNBS $(N=7-8 /$ day $), \mathrm{MP}+\mathrm{VEH}(N=7 /$ day $), \mathrm{PP}+$ TNBS $(N=5-8 /$ day $), \mathrm{PP}+\mathrm{VEH}(N=5-7 /$ day $)$; $* P<0.05$ and $* * * P<0.001$ by two-way ANOVA with Tukey's post hoc analysis. group. Tolerance was observed as early as day 2, and by day 3 they were completely tolerant $(20.9 \% \pm 13.5 \% \mathrm{MPE})$. Collectively, these findings indicate that antinociceptive tolerance to chronic morphine exposure in the presence of colonic inflammation is enhanced and occurred in a dose- and time-dependent manner.

We next determined the time course of IL- $1 \beta$ expression in the colon from each of these groups. The IL- $1 \beta$ mRNA expression in the 25-mg MP $+\mathrm{VEH}$ and $\mathrm{PP}+\mathrm{VEH}$ groups was not significantly altered over 5 days (Fig. 5A). However, IL-1 $\beta$ mRNA expression was significantly increased in TNBStreated groups. Morphine treatment did not enhance the expression of IL- $1 \beta$ over the levels induced by TNBS in any of the groups. These results indicate that the level of inflammation produced by TNBS alone masks any potential increase in the inflammation induced by morphine over this time frame.

Peripheral Opioid Receptor Antagonist Prevented the Development of Antinociceptive Tolerance. To test the role of peripheral $\mu$-opioid receptors in the development of tolerance induced by colonic inflammation, mice were treated with $6 \beta-N$-heterocyclic-substituted naltrexamine derivative (NAP), a peripheral $\mu$-opioid receptor antagonist. NAP was administered daily at a dose of $0.5 \mathrm{mg} / \mathrm{kg}$ s.c. To confirm the peripheral selectivity of NAP, we initially evaluated the effect of NAP on morphine-induced antinociception. NAP was administered at doses ranging from 0.1 to $5.0 \mathrm{mg} / \mathrm{kg} 30$ minutes prior to testing the analgesic effects of morphine in the warm-water tail-immersion assay. Supplemental Fig. 1 shows that NAP did not affect morphine-mediated antinociception at lower doses but only significantly reduced it at $5 \mathrm{mg} / \mathrm{kg}$. This is consistent with our previous report of NAP as a peripherally restricted $\mu$-opioid receptor antagonist. At lower doses it substantially reverses morphine-induced inhibition of gastrointestinal transit but not centrally mediated antinociception (Li et al., 2009; Yuan et al., 2011, 2012). NAP also produced diarrhea in both inflamed and noninflamed MP mice within 20 minutes of administration (data not shown).

As shown in Fig. 6, NAP reversed the enhanced tolerance that developed in TNBS-treated groups in each of the morphine-pelleted cohorts. Tolerance was determined by a challenge dose of morphine $(10 \mathrm{mg} / \mathrm{kg})$ in the tailimmersion assay at day 5 in the 25-mg MP group, at day 4 in the 50-mg MP group, and at day 3 in the 75-mg MP group. At these different time periods for each of the morphinepelleted cohorts, tolerance is only evident in the MP + TNBS 
A

Day 1

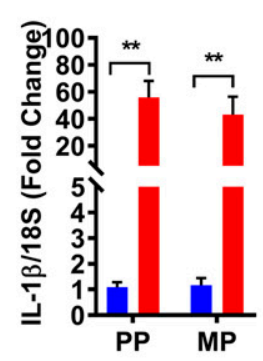

B

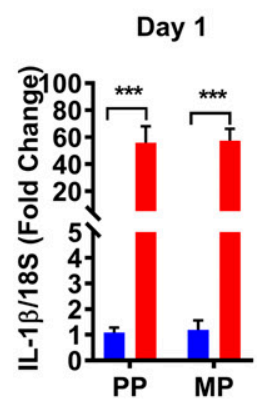

C

Day 1

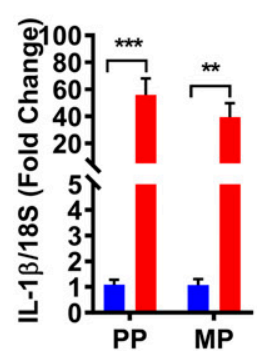

Day 2

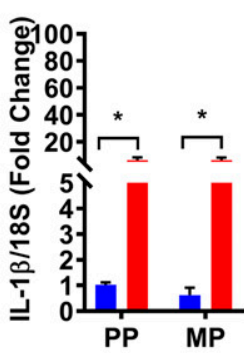

Day 2

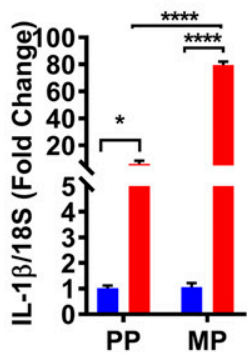

Day 2

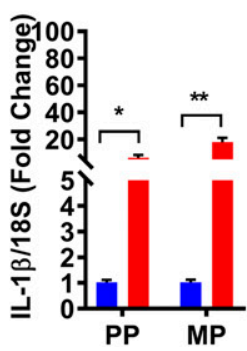

$25 \mathrm{mg}$ MP

Day 3

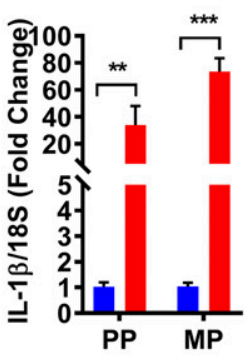

$50 \mathrm{mg}$ MP

Day 3

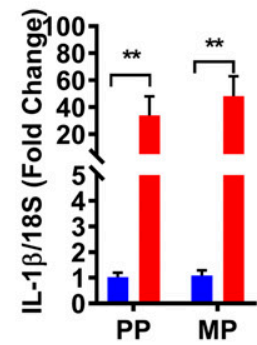

$75 \mathrm{mg}$ MP

Day 3

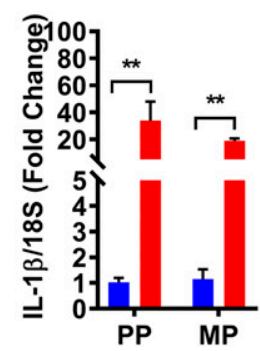

Day 4

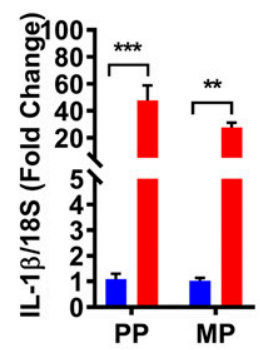

Day 4
Day 5

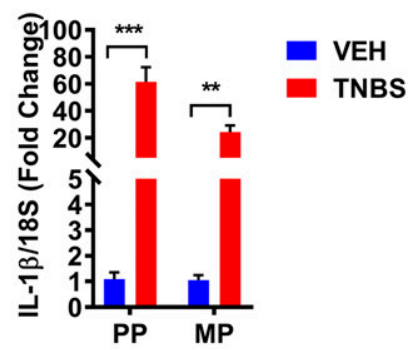

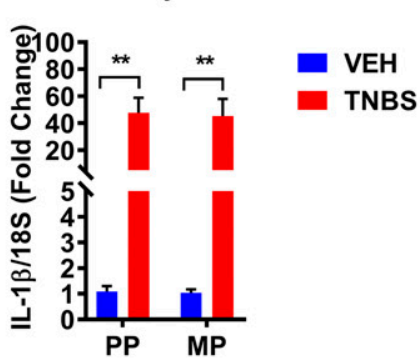

- VEH

- TNBS

Fig. 5. TNBS treatment induced the gene expression of proinflammatory cytokine IL- $1 \beta$. (A-C) Increased IL- $1 \beta$ mRNA expression observed in TNBStreated mice in the presence of (A) 25-mg MP, (B) 50-mg MP, and (C) 75-mg MP. IL-1 $\beta$ expressions are not significantly different between the MP + TNBS and PP + TNBS groups, and between MP + VEH and PP + VEH groups. $N=5$ /group $* P<0.05, * * P<0.01, * * * P<0.001$, and $* * * * P<0.0001$ by two-way ANOVA with Tukey's post hoc analysis.

groups. Daily injections of NAP prevented the development of tolerance.

Because tolerance to morphine does not develop in the absence of inflammation in the time frame in which we tested reversal by NAP, we therefore extended the challenge dose to 7 days following 75-mg morphine pellet. Figure 7A shows that tolerance develops on day 7 in 75-mg morphinepelleted mice. This was reduced by daily NAP treatment. Figure 7B shows cumulative dose-response curves in 7-day placebo and morphine-pelleted mice treated with NAP. There was a significant leftward shift in the 75-mg MP + NAP dose-response curve compared with MP + VEH. This finding shows that inhibition of peripheral opioid receptors prevents the development of antinociceptive tolerance to morphine.

To test if NAP reduced colonic inflammation, IL-1 $\beta$ mRNA expression was measured from the colons of 50-mg $\mathrm{MP}+\mathrm{TNBS}$ mice that were treated with NAP $(0.5 \mathrm{mg} / \mathrm{kg})$ after 4 days. The expression of IL- $1 \beta$ was not reduced by daily NAP treatment in the TNBS inflamed groups
(Fig. 8A). Similarly, gut permeability, which was determined by FITC-dextran concentration in blood plasma, was increased in TNBS-treated mice and in mice treated with morphine alone. However, NAP treatment did not reduce gut permeability (Fig. $8 \mathrm{~B}$ ). These findings suggest that NAP does not reduce colonic inflammation or epithelial permeability in the presence of TNBS but prevents antinociceptive tolerance.

\section{Discussion}

In the present study, we found that colonic inflammation enhances the rate and extent of antinociceptive tolerance to morphine. These findings may have major clinical implications for IBD patients using narcotic opioids. There is growing evidence that opioids may be a risk factor for IBD patients, as these drugs increase the severity of the disease, the risk of infection and mortality, as well as the risk of becoming heavy opioid users (Cross et al., 2005; Hanson et al., 2009; Long et al., 2012; Targownik et al., 2014). Clinical data 

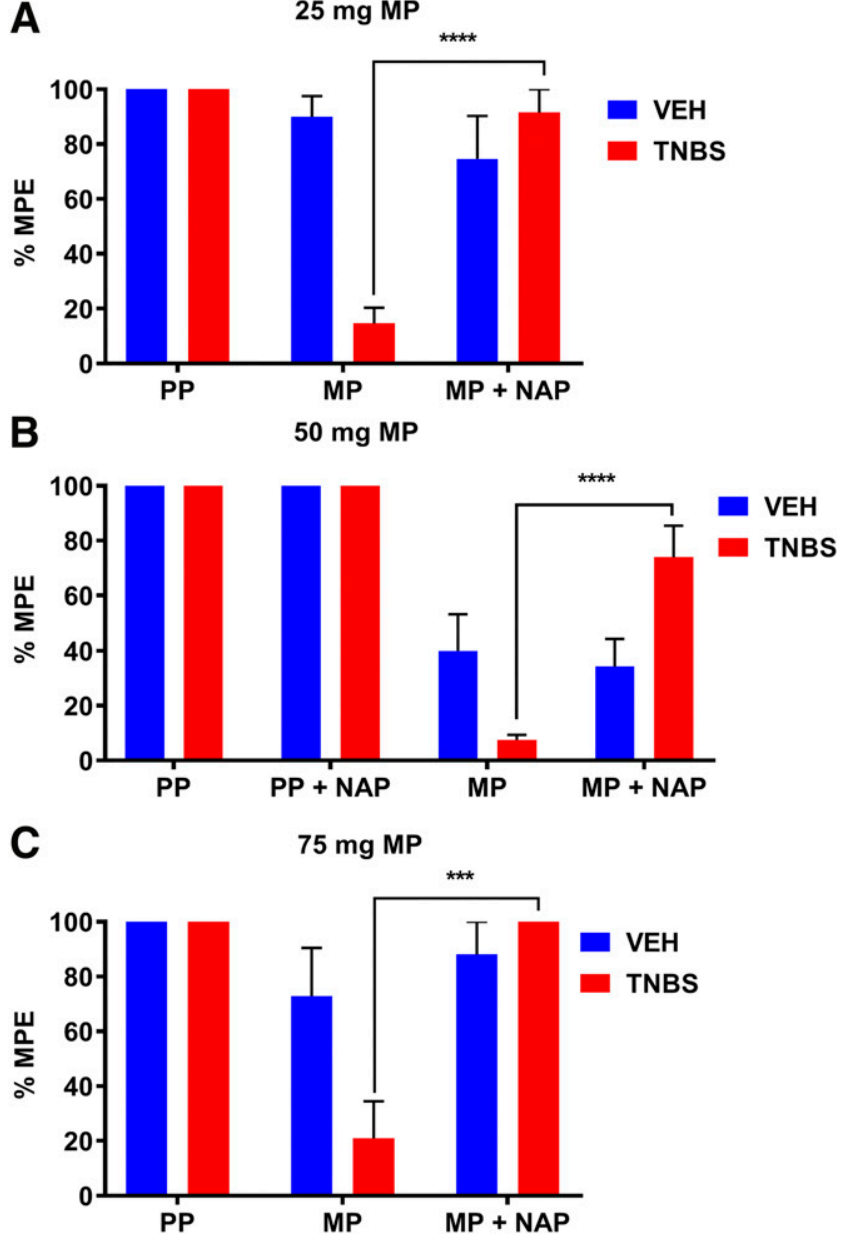

Fig. 6. Peripheral opioid receptor antagonist NAP prevented the enhanced development of morphine antinociceptive tolerance in TNBStreated mice. (A-C) Daily subcutaneous injection of $0.5 \mathrm{mg} / \mathrm{kg}$ NAP significantly attenuated the development of antinociceptive tolerance to morphine challenge $(10 \mathrm{mg} / \mathrm{kg})$ in $25-, 50-$, and $75-\mathrm{mg} \mathrm{MP}+$ TNBS + NAP mice compared with 25-, 50-, and 75-mg MP + TNBS mice on days 5,4 , and 3 , respectively. (A) MP + TNBS $(N=10), \mathrm{MP}+\mathrm{TNBS}+\mathrm{NAP}$ $(N=5), \mathrm{MP}+\mathrm{VEH}(N=12), \mathrm{MP}+\mathrm{VEH}+\mathrm{NAP}(N=5), \mathrm{PP}+\mathrm{TNBS}$ $(N=5), \mathrm{PP}+\mathrm{VEH}(N=5) ; * * * * P<0.0001$ by two-way ANOVA with Tukey's post hoc analysis. (B) MP + TNBS $(N=10)$, MP + TNBS + $\mathrm{NAP}(N=10), \mathrm{MP}+\mathrm{VEH}(N=10), \mathrm{MP}+\operatorname{VEH}+\operatorname{NAP}(N=10)$, $\mathrm{PP}+\mathrm{TNBS}(N=6), \mathrm{PP}+\mathrm{TNBS}+\mathrm{NAP}(N=5), \mathrm{PP}+\mathrm{VEH}(N=6)$, $\mathrm{PP}+\mathrm{VEH}+\mathrm{NAP}(N=7) ; * * * * P<0.0001$ by two-way ANOVA with Tukey's post hoc analysis. (C) MP + TNBS $(N=7)$, MP + TNBS + $\mathrm{NAP}(N=5), \mathrm{MP}+\mathrm{VEH}(N=7), \mathrm{MP}+\mathrm{VEH}+\mathrm{NAP}(N=5), \mathrm{PP}+$ TNBS $(N=8), \mathrm{PP}+\mathrm{VEH}(N=5) ; * * * P=0.0004$ by two-way ANOVA with Tukey's post hoc analysis.

have shown that prior opioid use before diagnosis with IBD predisposes patients to heavy opioid use later in life, and about $5 \%$ of IBD patients using opioids become heavy opioid users (Targownik et al., 2014). The enhanced rate of development of tolerance to morphine in the presence of colonic inflammation may be an important factor in predisposing patients to increased opioid use, thus setting up a vicious cycle.

While inflammation-mediated tolerance to morphine has been reported in an experimental arthritis model with complete Freund's adjuvant (Li et al., 1999; Fernández-Dueñas et al., 2007 ), to our knowledge, the present study is the first demonstration of the differential rate of morphine tolerance in an experimental colitis model and its reversal by a peripheral
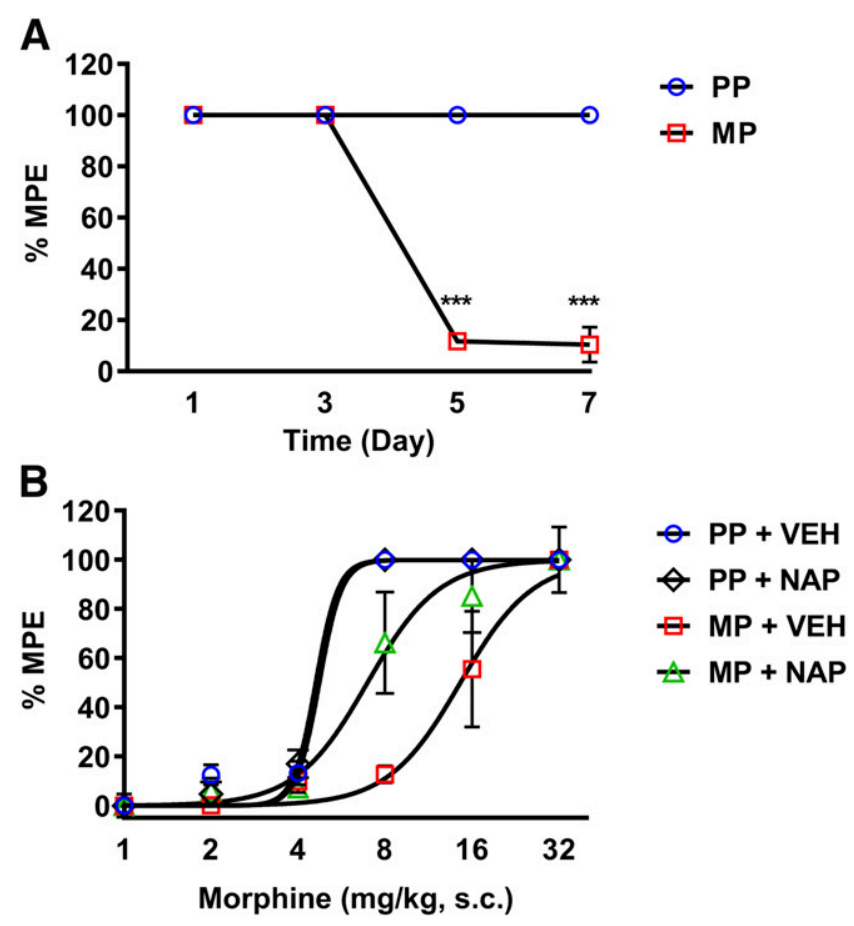

Fig. 7. Peripheral opioid receptor antagonist NAP prevented the development of morphine-induced antinociceptive tolerance. (A) Chronic morphine exposure $(75 \mathrm{mg})$ resulted in antinociceptive tolerance to morphine challenge $(10 \mathrm{mg} / \mathrm{kg})$ in the tail-immersion assay after 5 days of exposure. $N=5$ /group; $* * * P<0.001$ by two-way ANOVA with Bonferroni's post hoc analysis. (B) Daily NAP injection prevented the development of antinociceptive tolerance in morphine-pelleted mice on day 7 , indicated by the leftward shift in the cumulative morphine doseresponse curve $(1,2,4,8,16$, and $32 \mathrm{mg} / \mathrm{kg}) . N=5$ /group; $\mathrm{PP}+\mathrm{VEH}$ $\mathrm{ED}_{50}=4.74 \mathrm{mg} / \mathrm{kg} ; \mathrm{PP}+\mathrm{NAP} \mathrm{ED}_{50}=4.61 \mathrm{mg} / \mathrm{kg} ; \mathrm{MP}+\mathrm{VEH} \mathrm{ED} \mathrm{ED}_{50}=$ $14.57 \mathrm{mg} / \mathrm{kg}\left(11.13-18.4,95 \%\right.$ confidence limit (C.L.)); $\mathrm{MP}+\mathrm{NAP} \mathrm{ED}_{50}=$ $6.95 \mathrm{mg} / \mathrm{kg}(5.54-8.92,95 \%$ confidence limit (C.L.)) with nonlinear regression analysis (best-fit lines).

opioid antagonist. The TNBS-induced inflammation is suggested to model Crohn's disease in terms of both clinical and histopathological findings (Strober et al., 1998; Antoniou et al., 2016). In the experimental colitis model, inflamed mice were more sensitive to acute morphine (Fig. 2). Previous studies by Fernández-Dueñas et al. (2007) also found increased sensitivity to acute morphine in the presence of complete Freund's adjuvant-induced inflammation. The increase morphine potency in inflamed mice indicated by the leftward shift in the dose-response curve could be due to the increase in $\mu$-opioid receptor (MOR) expression during inflammation (Philippe et al., 2006), which aligns with previous studies in rodents demonstrating the association of peripheral inflammation with increased MOR axonal transport (Hassan et al., 1993; Jeanjean et al., 1995; Mousa et al., 2001). The peripheral axonal transport of MOR during an inflammatory state is thought to be mediated by cytokine production and nerve growth factor (Stein and Lang, 2009), resulting in enhanced antinociceptive efficacy of morphine.

The development of tolerance to morphine was tested by providing a challenge dose of $10 \mathrm{mg} / \mathrm{kg}$ morphine in chronic morphine-treated mice. Interestingly, while inflammation alone did not induce tolerance to morphine, tolerance occurred with the lowest dose of morphine in the presence of colonic inflammation (Fig. 4A). These findings suggest that 
A

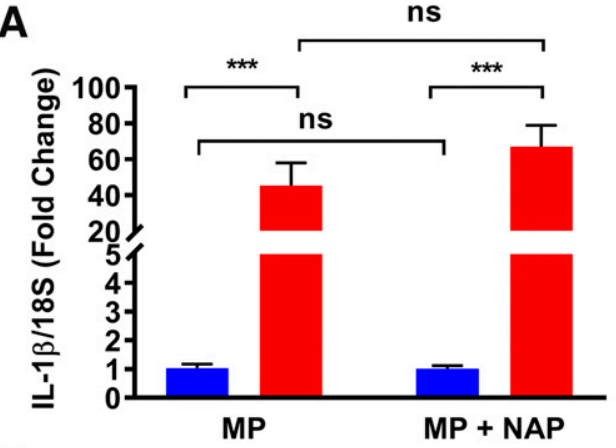

B

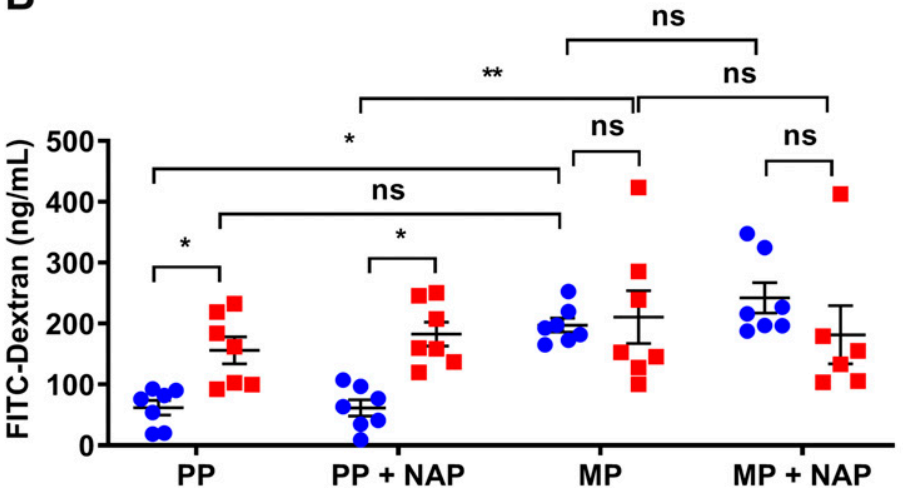

- VEH

TNBS

Fig. 8. Peripheral opioid receptor antagonist did not decrease TNBS-induced IL- $1 \beta$ mRNA expression. (A) IL-1 $\beta$ mRNA expression was not statistically different between 50-mg MP + TNBS + NAP and 50-mg MP + TNBS groups on day $4 . N=5$ /group; ns, not significant; *** $P<0.001$ by two-way ANOVA with Tukey's post hoc analysis. (B) Fluorometric quantification of FITC from blood serum showed a significant fluorescence concentration in all groups except for PP + VEH and PP + VEH + NAP groups. Daily NAP injection did not block membrane permeability in 50 -mg MP + TNBS + NAP mice. $N=6$ to $7 ; * P<0.05$ and $* * P<0.01$ by two-way ANOVA with Tukey's post hoc analysis.

inflammation sensitizes the process of tolerance development. A possible mechanism may involve the release of endogenous opioid peptides, specifically $\beta$ endorphins, under inflammatory conditions that may, in combination with the presence of morphine, lead to rapid desensitization of the $\mu$-opioid receptor, resulting in greater tolerance (Stein et al., 1990a,b; Cabot et al., 1997). Another possibility for the enhanced tolerance could be due to gut-derived mediators that may render tolerance to morphine in primary afferent neurons emanating from the colon. We recently reported that colonic supernatants from morphine-treated mice render tolerance in the isolated dorsal root ganglion neurons (Mischel et al., 2018).

It is noteworthy that the development of tolerance to morphine was prevented by a peripheral MOR antagonist. We have previously reported that NAP, a naltrexamine derivative, is a peripherally selective $\mu$-opioid receptor antagonist ( $\mathrm{Li}$ et al., 2009; Yuan et al., 2012). Unlike methylnaltrexone, which can be demethylated and have central effects in rodents (Kotake et al., 1989; Chandrasekaran et al., 2010; unpublished data), NAP did not block acute effects of morphine on antinociception (Supplemental Fig. 1) but did reverse morphine-induced inhibition of gastrointestinal motility (Yuan et al., 2012). At a dose that did not affect centrally mediated antinociception, NAP reversed the antinociceptive tolerance irrespective of the presence of inflammation, suggesting that inhibition of the $\mu$-opioid receptors in the peripheral sites was sufficient to prevent tolerance development. NAP has high binding affinity for MOR, with more than 700-fold and 150-fold selectivity over $\delta$ - and $\kappa$-opioid receptors, respectively (Li et al., 2009; Yuan et al., 2012). A peripheral component for the tolerance to opioids has also been reported recently by Corder et al. (2017), wherein methylnaltrexone bromide, a clinically available peripheral MOR antagonist, prevented the development of tolerance and opioid-induced hyperalgesia without affecting morphine's antinociceptive effects.

Given that the peripheral contribution is necessary for the development of tolerance, IBD patients may need to take a peripheral opioid receptor antagonist to prevent the development of analgesic tolerance. Methylnaltrexone and alvimopan are peripheral opioid receptor antagonists currently used in the clinic for treatment of opioid-induced constipation and postoperative ileus, respectively. Up to now, there are no clinical studies that have directly assessed the use of peripheral opioid receptor antagonists in IBD patients to prevent analgesic tolerance. There are clinical studies that have investigated the use of low-dose naltrexone in IBD patients to decrease colonic inflammation and prolong remission in these patients (Younger et al., 2014; Raknes and Småbrekke, 2017; Lie et al., 2018; Raknes et al., 2018). This is thought to be mediated via nonopioid receptors, such as Toll-like receptor 4 (TLR4) (Younger et al., 2014). Low-dose naltrexone binds TLR4 as an antagonist on immune cells and prevents the release of inflammatory mediators. It is possible that NAP did not reduce colonic inflammation in our study, as it may not have an affinity for TLR4 or act on immune cells. Unlike naltrexone, which can act as a nonselective antagonist on both classic opioid receptors and TLR4 (depending on the dose), NAP only acts selectively on $\mu$-opioid receptors as an antagonist peripherally.

In conclusion, the rate of morphine tolerance has a dose and time dependency that is greatly enhanced in the presence of inflammation. The enhanced rate of tolerance is not a direct effect of inflammation per se, but rather a receptor-mediated effect. Cytokines released during the inflammatory state may directly or indirectly modulate the sensitivity of the receptors, thus altering intracellular signaling and affecting antinociceptive tolerance. In the presence of NAP, this effect was attenuated (Fig. 9). Our findings suggest a potential 
A

\section{Normal Condition}

Morphine

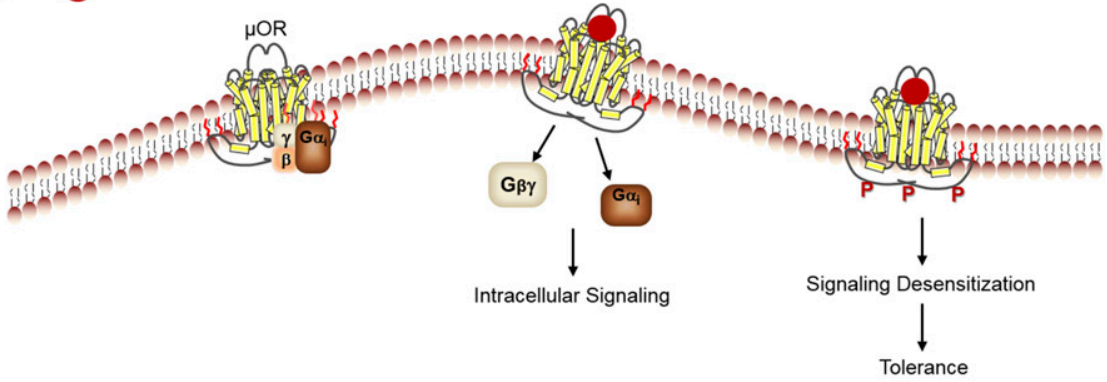

B

Inflammatory Condition

Morphine

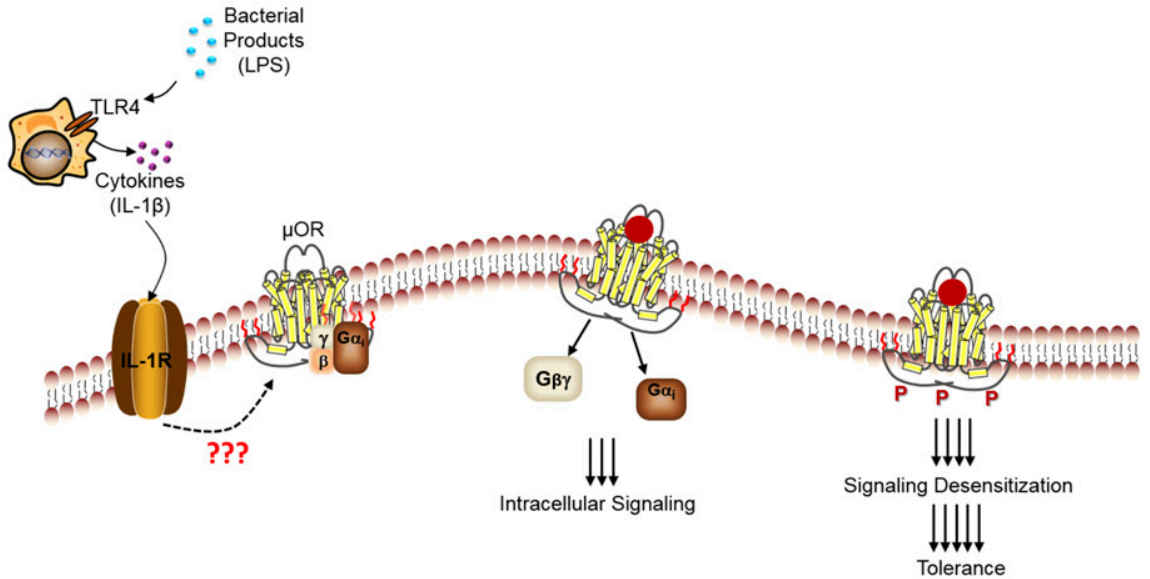

C Inflammatory Condition + Peripheral Antagonist

Morphine NAP
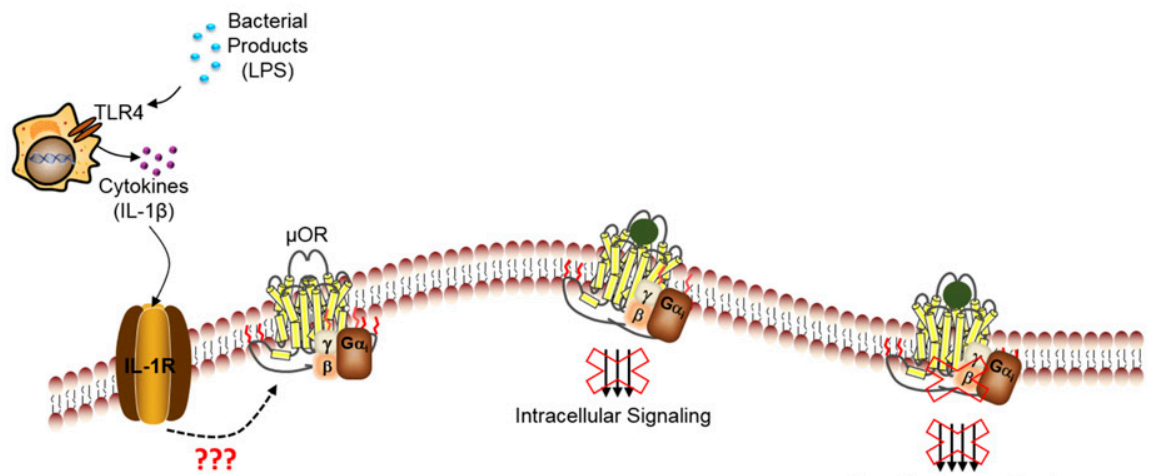

Signaling Desensitization

朻

Tolerance
Fig. 9. Proposed schematic of the reversal of antinociceptive tolerance by NAP. (A) Under a normal condition, when morphine is used, it binds to MOR, activates the receptor, and induces downstream intracellular signaling. Continual activation of the receptor by morphine results in signaling desensitization, leading to morphine-induced tolerance. (B) During an inflammatory condition, cytokines released from immune cells may interact with the MOR directly or indirectly, resulting in a potent morphine response upon binding, leading to an enhanced rate of tolerance development. (C) In the presence of a peripheral antagonist, NAP, the enhanced morphine tolerance that developed is blocked. LPS, (lipopolysaccharide). therapeutic avenue for peripheral opioid receptor antagonists to attenuate the development of opioid tolerance without affecting analgesia.

\section{Authorship Contributions}

Participated in research design: Komla, Akbarali.

Conducted experiments: Komla, Stevens.

Contributed new reagents or analytic tools: Komla, Zhang, Zheng, Dewey, Akbarali.

Performed data analysis: Komla, Akbarali.
Wrote or contributed to the writing of the manuscript: Komla, Dewey, Akbarali.

\section{References}

Antoniou E, Margonis GA, Angelou A, Pikouli A, Argiri P, Karavokyros I, Papalois A, and Pikoulis E (2016) The TNBS-induced colitis animal model: an overview. Ann Med Surg (Lond) 11:9-15.

Bhave S, Gade A, Kang M, Hauser KF, Dewey WL, and Akbarali HI (2017) Connexinpurinergic signaling in enteric glia mediates the prolonged effect of morphine on constipation. FASEB $J$ 31:2649-2660.

Cabot PJ, Carter L, Gaiddon C, Zhang Q, Schäfer M, Loeffler JP, and Stein C (1997) Immune cell-derived beta-endorphin. Production, release, and control of inflammatory pain in rats. $J$ Clin Invest 100:142-148. 
Chandrasekaran A, Tong Z, Li H, Erve JCL, DeMaio W, Goljer I, McConnell O, Rotshteyn Y, Hultin T, Talaat R, et al. (2010) Metabolism of intravenous methylnaltrexone in mice, rats, dogs, and humans. Drug Metab Dispos 38:606-616.

Corder G, Tawfik VL, Wang D, Sypek EI, Low SA, Dickinson JR, Sotoudeh C, Clark JD, Barres BA, Bohlen CJ, et al. (2017) Loss of $\mu$ opioid receptor signaling in nociceptors, but not microglia, abrogates morphine tolerance without disrupting analgesia. Nat Med 23:164-173.

Cross RK, Wilson KT, and Binion DG (2005) Narcotic use in patients with Crohn's disease. Am J Gastroenterol 100:2225-2229.

Fernández-Dueñas V, Pol O, García-Nogales P, Hernández L, Planas E, and Puig MM (2007) Tolerance to the antinociceptive and antiexudative effects of morphine in a murine model of peripheral inflammation. J Pharmacol Exp Ther 322:360-368.

Hanson KA, Loftus EV Jr, Harmsen WS, Diehl NN, Zinsmeister AR, and Sandborn WJ (2009) Clinical features and outcome of patients with inflammatory bowel disease who use narcotics: a case-control study. Inflamm Bowel Dis 15:772-777.

Hassan AHS, Ableitner A, Stein C, and Herz A (1993) Inflammation of the rat paw enhances axonal transport of opioid receptors in the sciatic nerve and increases their density in the inflamed tissue. Neuroscience 55:185-195.

Hayhurst CJ and Durieux ME (2016) Differential opioid tolerance and opioid-induced hyperalgesia: a clinical reality. Anesthesiology 124:483-488.

Hutchinson MR, Coats BD, Lewis SS, Zhang Y, Sprunger DB, Rezvani N, Baker EM, Jekich BM, Wieseler JL, Somogyi AA, et al. (2008) Proinflammatory cytokines oppose opioid-induced acute and chronic analgesia. Brain Behav Immun 22:1178-1189.

Jeanjean AP, Moussaoui SM, Maloteaux J-M, and Laduron PM (1995) Interleukin-1 $\beta$ induces long-term increase of axonally transported opiate receptors and substance P. Neuroscience 68:151-157.

Johnston IN, Milligan ED, Wieseler-Frank J, Frank MG, Zapata V, Campisi J, Langer S, Martin D, Green P, Fleshner M, et al. (2004) A role for proinflammatory cytokines and fractalkine in analgesia, tolerance, and subsequent pain facilitation induced by chronic intrathecal morphine. J Neurosci 24:7353-7365.

Kang M, Mischel RA, Bhave S, Komla E, Cho A, Huang C, Dewey WL, and Akbarali HI (2017) The effect of gut microbiome on tolerance to morphine mediated antinociception in mice. Sci Rep 7:42658.

Kotake AN, Kuwahara SK, Burton E, McCoy CE, and Goldberg LI (1989) Variations in demethylation of $\mathrm{N}$-methylnaltrexone in mice, rats, dogs, and humans. Xenobiotica 19:1247-1254.

Lee K, Vuong HE, Nusbaum DJ, Hsiao EY, Evans CJ, and Taylor AMW (2018) The gut microbiota mediates reward and sensory responses associated with regimenselective morphine dependence. Neuropsychopharmacology 43:2606-2614.

Li G, Aschenbach LC, Chen J, Cassidy MP, Stevens DL, Gabra BH, Selley DE, Dewey WL, Westkaemper RB, and Zhang Y (2009) Design, synthesis, and biological evaluation of 6alpha- and 6beta-N-heterocyclic substituted naltrexamine derivatives as mu opioid receptor selective antagonists. J Med Chem 52:1416-1427.

Li JY, Wong CH, Huang KS, Liang KW, Lin MY, Tan PPC, and Chen JC (1999) Morphine tolerance in arthritic rats and serotonergic system. Life Sci 64:PL111-PL116.

Lichtenstein GR, Feagan BG, Cohen RD, Salzberg BA, Diamond RH, Chen DM, Pritchard ML, and Sandborn WJ (2006) Serious infections and mortality in association with therapies for Crohn's disease: TREAT registry. Clin Gastroenterol Hepatol 4:621-630.

Lichtenstein GR, Feagan BG, Cohen RD, Salzberg BA, Diamond RH, Price S, Langholff W, Londhe A, and Sandborn WJ (2012) Serious infection and mortality in patients with Crohn's disease: more than 5 years of follow-up in the TREAT ${ }^{\mathrm{TM}}$ registry. Am J Gastroenterol 107:1409-1422.

Lie MRKL, van der Giessen J, Fuhler GM, de Lima A, Peppelenbosch MP, van der Ent C, and van der Woude CJ (2018) Low dose Naltrexone for induction of remission in inflammatory bowel disease patients. J Transl Med 16:55.

Long MD, Barnes EL, Herfarth HH, and Drossman DA (2012) Narcotic use for in flammatory bowel disease and risk factors during hospitalization. Inflamm Bowel Dis 18:869-876.
Meng J, Yu H, Ma J, Wang J, Banerjee S, Charboneau R, Barke RA, and Roy S (2013) Morphine induces bacterial translocation in mice by compromising intestinal barrier function in a TLR-dependent manner. PLoS One 8:e54040.

Milligan ED and Watkins LR (2009) Pathological and protective roles of glia in chronic pain. Nat Rev Neurosci 10:23-36.

Mischel RA, Dewey WL, and Akbarali HI (2018) Tolerance to morphine-induced inhibition of TTX-R sodium channels in dorsal root ganglia neurons is modulated by gut-derived mediators, iScience 2, pp 193-209.

Mousa SA, Zhang Q, Sitte N, Ji R, and Stein C (2001) $\beta$-Endorphin-containing memory-cells and $\mu$-opioid receptors undergo transport to peripheral inflamed tissue. J Neuroimmunol 115:71-78.

Philippe D, Chakass D, Thuru X, Zerbib P, Tsicopoulos A, Geboes K, Bulois P, Breisse M, Vorng H, Gay J, et al. (2006) Mu opioid receptor expression is increased in inflammatory bowel diseases: implications for homeostatic intestinal inflammation. Gut 55:815-823.

Raghavendra V, Rutkowski MD, and DeLeo JA (2002) The role of spinal neuroimmune activation in morphine tolerance/hyperalgesia in neuropathic and sham-operated rats. J Neurosci 22:9980-9989.

Raghavendra V, Tanga FY, and DeLeo JA (2004) Attenuation of morphine tolerance, withdrawal-induced hyperalgesia, and associated spinal inflammatory immune responses by propentofylline in rats. Neuropsychopharmacology 29:327-334.

Raknes G, Simonsen P, and Småbrekke L (2018) The effect of low-dose naltrexone on medication in inflammatory bowel disease: a quasi experimental before-and-after prescription database study. J Crohn's Colitis 12:677-686.

Raknes G and Småbrekke L (2017) Low-dose naltrexone and opioid consumption: a drug utilization cohort study based on data from the Norwegian prescription database. Pharmacoepidemiol Drug Saf 26:685-693.

Song $\mathrm{P}$ and Zhao Z-Q (2001) The involvement of glial cells in the development of morphine tolerance. Neurosci Res 39:281-286.

Stein C, Gramsch C, and Herz A (1990a) Intrinsic mechanisms of antinociception in inflammation: local opioid receptors and beta-endorphin. J Neurosci 10:1292-1298.

Stein C, Hassan AH, Przewłocki R, Gramsch C, Peter K, and Herz A (1990b) Opioids from immunocytes interact with receptors on sensory nerves to inhibit nociception in inflammation. Proc Natl Acad Sci USA 87:5935-5939.

Stein C and Lang LJ (2009) Peripheral mechanisms of opioid analgesia. Curr Opin Pharmacol 9:3-8.

Strober W, Lúdvíksson BR, and Fuss IJ (1998) The pathogenesis of mucosal inflammation in murine models of inflammatory bowel disease and Crohn disease. Ann Intern Med 128:848-856.

Targownik LE, Nugent Z, Singh H, Bugden S, and Bernstein CN (2014) The prevalence and predictors of opioid use in inflammatory bowel disease: a population-based analysis. Am J Gastroenterol 109:1613-1620.

Watkins LR, Hutchinson MR, Johnston IN, and Maier SF (2005) Glia: novel counterregulators of opioid analgesia. Trends Neurosci 28:661-669.

Younger J, Parkitny L, and McLain D (2014) The use of low-dose naltrexone (LDN) as a novel anti-inflammatory treatment for chronic pain. Clin Rheumatol 33:451-459.

Yuan Y, Li G, He H, Stevens DL, Kozak P, Scoggins KL, Mitra P, Gerk PM, Selley DE, Dewey WL, et al. (2011) Characterization of $6 \alpha$ - and $6 \beta-N-h$ terocyclic substituted naltrexamine derivatives as novel leads to development of mu opioid receptor selective antagonists. ACS Chem Neurosci 2:346-351.

Yuan Y, Stevens DL, Braithwaite A, Scoggins KL, Bilsky EJ, Akbarali HI, Dewey WL, and Zhang Y (2012) 63-N-heterocyclic substituted naltrexamine derivative NAP as a potential lead to develop peripheral mu opioid receptor selective antagonists. Bioorg Med Chem Lett 22:4731-4734.

Address correspondence to: Dr. Hamid I. Akbarali, Department of Pharmacology and Toxicology, Virginia Commonwealth University, 1112 E. Clay Street, Richmond, VA 23298. E-mail: Hamid.akbarali@vcuhealth.org 